Pesq. Vet. Bras. 30(3):277-288, março 2010

\title{
Aspectos toxicológico, clínico-patológico e ultraestrutural das intoxicações iatrogênica e experimental por vitamina $D$ em coelhos ${ }^{1}$
}

INDEX TERMS: Cholecalciferol, hypervitaminosis D, pathology, rabbits.

RESUMO.- São descritos aspectos toxicológicos, clínico-patológicos e ultraestruturais de coelhos intoxicados iatrogênica e experimentalmente por vitamina $D$ por via subcutânea. Clinicamente, os animais evidenciaram sinais de insuficiência cardiovascular como ascite e edema pulmonar, hiporexia, anorexia, diarréia mucosa, emagrecimento e apatia. As clássicas alterações de mineralização e, por vezes, osseificação, do sistema cardiovascular, bem como as alterações de rins, pulmões, estômago, entre outros órgãos, foram reproduzidas com administra-

\footnotetext{
${ }^{1}$ Recebido em 13 de outubro de 2009.

Aceito para publicação em 13 de dezembro de 2009.

Parte da Dissertação de Mestrado do segundo autor, Programa de Pós-Graduação em Medicina Veterinária, Universidade Federal Rural do Rio de Janeiro (UFRRJ), Seropédica, RJ 23890-000, Brasil.

2 Departamento de Nutrição Animal e Pastagem, Instituto de Zootecnia, UFRRJ, Seropédica, RJ. Autor para correspondência: pvpeixoto@ufrrj.br

${ }^{3}$ Pós-graduação em Medicina Veterinária, UFRRJ, Seropédica, RJ.

${ }^{4}$ Departamento de Epidemiologia e Saúde Pública, Instituto de Veterinária, UFRRJ, Seropédica, RJ.

${ }^{5}$ Escola de Medicina Veterinária, Campus Castanhal, Universidade Federal do Pará (UFPA), Rua Maximino Porpino 1000, Castanhal, PA 68743-080, Brasil.
}

ções subcutâneas de solução oleosa de colecalciferol (vitamina D3 não-ativada).

TERMOS DE INDEXAÇÃO: Colecalciferol, hipervitaminose D, patologia, coelhos.

\section{INTRODUÇÃO}

Por mais contraditório que possa parecer, a vitamina $D$ é uma das substâncias mais tóxicas que se conhecem. Uma pessoa adulta, com função da paratireóide e sensibilidade à vitamina $D$ normais, pode se intoxicar com a ingestão diária de aproximadamente $1,25 \mathrm{mg}$ de vitamina $\mathrm{D}$ (Marcus 1996). As calcinoses, enfermidades caracterizadas por extensa mineralização de tecidos moles, representam a principal manifestação clínico-patológica do envenenamento direto ou indireto por vitamina $\mathrm{D}$.

As intoxicações por plantas que contêm substâncias calcinogênicas são bem conhecidas em todo o mundo e ocorrem em diversas espécies animais (Mello \& Habermehl 1995). Essas enfermidades naturais - também denominadas calcinoses - mimetizam o envenenamento por vitamina $\mathrm{D}$ em quase todos os aspectos.

A análise dos livros clássicos de Patologia Humana e Veterinária revela que essa intoxicação não parece estar 
convenientemente estudada e esclarecida. Em parte, tal se deve às complexas e, por vezes, obscuras relações que envolvem o metabolismo de cálcio, fósforo, vitamina $D$, paratormônio (PTH), calcitonina e de outros hormônios. Em relação à intoxicação por vitamina $D$, sabe-se que os coeIhos constituem excelente modelo para estudos experimentais (Barros et al. 1981). Uma das alterações patológicas mais importantes que se observam nos animais com hipervitaminose $D$ é o comprometimento do sistema cardiovascular, sobretudo pela mineralização das artérias.

O presente trabalho objetiva descrever aspectos toxicológico e clínico-patológico observados em coelhos intoxicados iatrogenicamente por vitamina $D$, em função da inadvertida administração dessa substância, por via subcutânea. Adicionalmente, em relação aos mesmos aspectos, são apresentados os resultados referentes à intoxicação experimental por vitamina $\mathrm{D}$, obtidos mediante administração de solução oleosa de colecalciferol em coelhos, também por via subcutânea.

\section{MATERIAL E MÉTODOS}

\section{Intoxicação iatrogênica}

Dois coelhos (51 e 52) intoxicados iatrogenicamente por vitamina $D$, oriundos do município de Seropédica, RJ, foram encaminhados ao Biotério do Setor de Anatomia Patológica do Projeto Sanidade Animal do Convênio UFRRJ/Embrapa com histórico de suplementação com composto vitamínico (vitaminas A, D e E) por via subcutânea, uma vez que houve suspeita de que os animais estariam com deficiência vitamínica. Não foram fornecidos dados sobre a dose administrada a cada um desses dois coelhos.

\section{Procedimento experimental}

Para o Experimento 1 foram utilizados nove coelhos com cerca de 140 dias de idade e pesos variando entre 2,7 e 3,7kg e, no Experimento 2, seis coelhos com cerca de 90 dias de idade e pesos variando entre 1,85 e $2,1 \mathrm{~kg}$. Todos os coelhos eram da raça Nova Zelândia e de ambos os sexos.
Nos Experimentos 1 e 2, os coelhos, previamente adaptados ao local (por 30 e 7 dias, respectivamente), receberam ração comercial ${ }^{6}$ para coelhos e água à vontade.

No Experimento 1, os coelhos receberam, no $1^{\circ}$ dia, 52,42 a $52,68 \mathrm{mg} / \mathrm{kg}$ de vitamina D3 (solução oleosa - azeite de oliva - de colecalciferol), na concentração de $86,2 \mathrm{mg} / \mathrm{ml}(3.448 .400$ $\mathrm{Ul} / \mathrm{ml}$ ). A $2^{\mathrm{a}}$ dose de vitamina D3 (mesma dosagem anterior) foi administrada no $4^{\circ}$ dia, 83 horas após a $1^{a}$ dose. Todos os animais, antes e durante o experimento, foram avaliados diariamente quanto ao estado geral, comportamento, ingestão de ração e aspecto das fezes. As necropsias foram realizadas após a morte espontânea dos coelhos, com exceção do Coelho 7, que se recuperou. (Quadro 1)

No Experimento 2, os coelhos foram separados em três grupos (G1, G2 e G3) e receberam, no $1^{\circ}$ dia, 50,81-52,66mg/ $\mathrm{kg}$ de vitamina D3 (solução oleosa de colecalciferol), na concentração de $86,21 \mathrm{mg} / \mathrm{ml}(3.448 .400 \mathrm{Ul} / \mathrm{ml})$. Os coelhos dos grupos G1 (A e B) e G2 (C e D) foram eutanasiados e necropsiados 40 e 88 horas depois da administração de vitamina D3, respectivamente. Os coelhos do grupo G3 ( $E$ e F) receberam a $2^{\mathrm{a}}$ dose de vitamina D3 (mesma dose anterior) após 85 horas e foram eutanasiados e necropsiados 136 horas após a $1^{\text {a }}$ aplicação de vitamina D3 para estudo das lesões. (Quadro 2)

Durante a necropsia, fragmentos de diversos órgãos destinados ao estudo histopatológico foram coletados de todos os coelhos intoxicados natural e experimentalmente, fixados em formol a $10 \%$, processados como de rotina e corados com HE.

Pequenos fragmentos de aorta e mucosa gástrica, dos animais submetidos à intoxicação experimental, foram coletados imediatamente após o óbito, fixados em solução de glutaraldeído a $2 \%$ em tampão cacodilato de sódio $(0,3 \mathrm{M} \mathrm{e} \mathrm{pH} 7,4)$ e enviados ao Setor de Patologia da Universidade Federal de Pelotas. Posteriormente, houve a pós-fixação em tetróxido de ósmio e embebição em resina Epon. Cortes semifinos foram corados com azul de metileno e ultrafinos com acetato de uranila e citrato de chumbo e observados em microscópio eletrônico de transmissão.

${ }^{6}$ Ração da Purina para coelhos

Quadro 1. Hipervitaminose D em coelhos (Exp.1). Delineamento experimental, evolução e desfecho

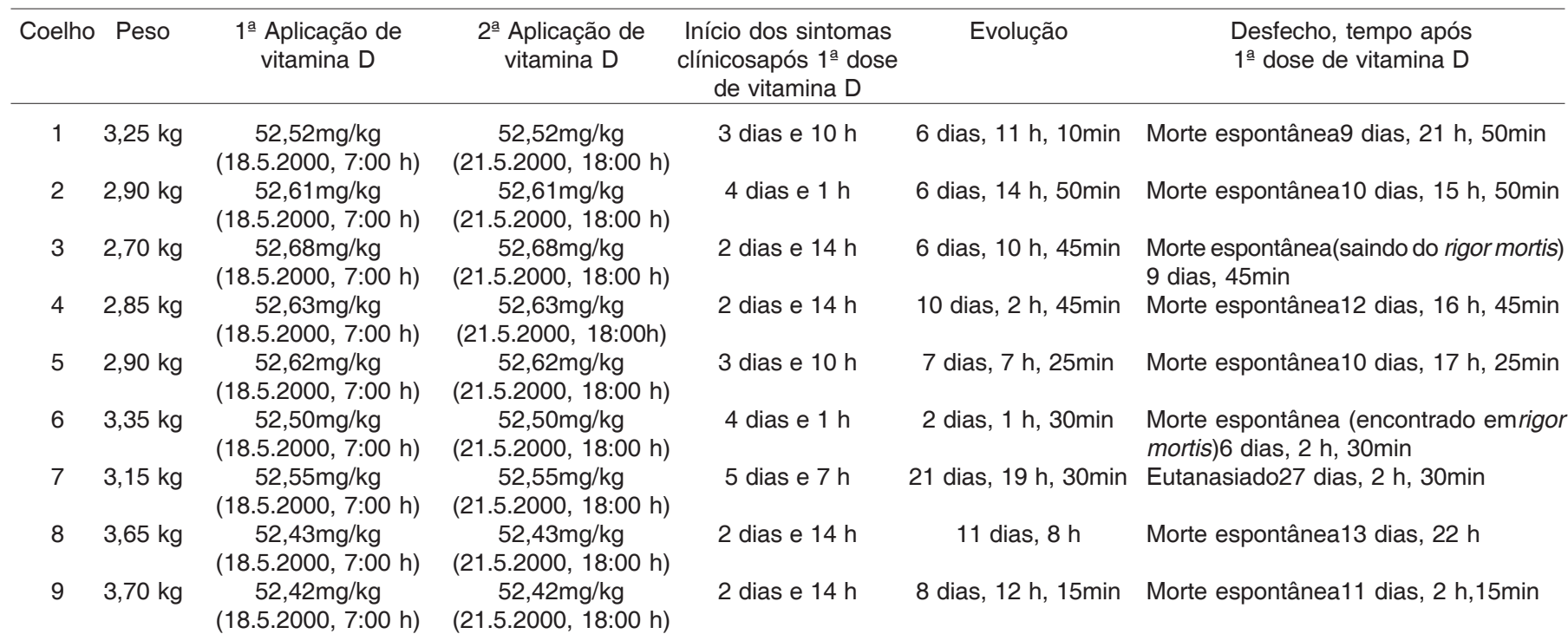


Quadro 2. Hipervitaminose D em coelhos (Exp.2). Delineamento experimental, evolução e desfecho

\begin{tabular}{|c|c|c|c|c|}
\hline Coelho & Peso & $\begin{array}{l}\text { 1 Aplicação de } \\
\text { vitamina D }\end{array}$ & $\begin{array}{l}2^{a} \text { Aplicação de } \\
\text { vitamina D }\end{array}$ & $\begin{array}{l}\text { Desfecho, tempo após } \\
1^{\text {1a }} \text { dose de vitamina } D\end{array}$ \\
\hline A & $2,05 \mathrm{~kg}$ & $\begin{array}{c}52,57 \mathrm{mg} / \mathrm{kg} \\
(23.9 .2000,18: 00 \mathrm{~h})\end{array}$ & - & $\begin{array}{c}\text { Eutanasiado } \\
1 \text { dia, } 16 \mathrm{~h}(40 \mathrm{~h})\end{array}$ \\
\hline B & $1,90 \mathrm{~kg}$ & $\begin{array}{c}52,63 \mathrm{mg} / \mathrm{kg} \\
(23.9 .2000,18: 00 \mathrm{~h})\end{array}$ & - & $\begin{array}{c}\text { Eutanasiado } \\
1 \mathrm{dia}, 16 \mathrm{~h}(40 \mathrm{~h})\end{array}$ \\
\hline C & $2,10 \mathrm{~kg}$ & $\begin{array}{c}52,55 \mathrm{mg} / \mathrm{kg} \\
(23.9 .2000,18: 00 \mathrm{~h})\end{array}$ & - & $\begin{array}{c}\text { Eutanasiado } \\
3 \text { dias, } 16 \text { h (88 h) }\end{array}$ \\
\hline D & $1,85 \mathrm{~kg}$ & $\begin{array}{c}52,66 \mathrm{mg} / \mathrm{kg} \\
(23.9 .2000,18: 00 \mathrm{~h})\end{array}$ & - & $\begin{array}{c}\text { Eutanasiado } \\
3 \text { dias, } 16 \text { h ( } 88 \text { h) }\end{array}$ \\
\hline$E$ & $1,95 \mathrm{~kg}$ & $\begin{array}{c}51,75 \mathrm{mg} / \mathrm{kg} \\
(23.9 .2000,18: 00 \mathrm{~h})\end{array}$ & $\begin{array}{c}51,75 \mathrm{mg} / \mathrm{kg} \\
(27.9 .2000,7: 00)\end{array}$ & $\begin{array}{c}\text { Eutanasiado } \\
5 \text { dias, } 16 \text { h (136 h) }\end{array}$ \\
\hline$F$ & $1,90 \mathrm{~kg}$ & $\begin{array}{c}50,81 \mathrm{mg} / \mathrm{kg} \\
(23.9 .2000,18: 00 \mathrm{~h})\end{array}$ & $\begin{array}{c}50,81 \mathrm{mg} / \mathrm{kg} \\
(27.9 .2000,7: 00)\end{array}$ & $\begin{array}{c}\text { Eutanasiado } \\
5 \text { dias, } 16 \mathrm{~h}(136 \mathrm{~h})\end{array}$ \\
\hline
\end{tabular}

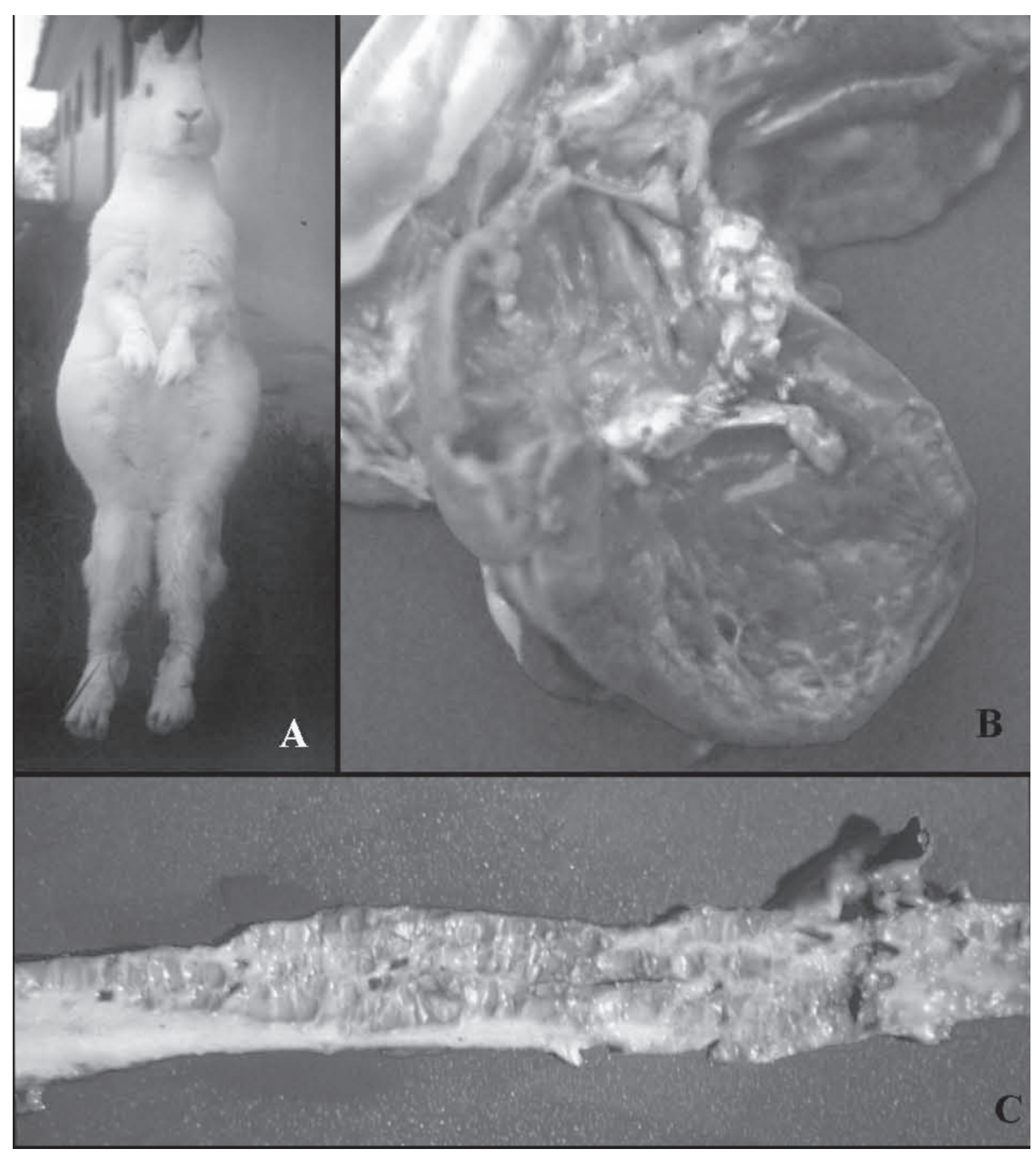

Fig.1. Intoxicação iatrogênica por vitamina D em coelhos. (A) Acentuada distensão abdominal por líquido ascítico decorrente da insuficiência cardíaca crônica por mineralização cardiovascular (Coelho 51). (B) Acentuada dilatação átrio-ventricular esquerda; valva mitral espessada, com formação de placas de mineralização (Coelho 51). (C) Intoxicação experimental por vitamina $\mathrm{D}$ em coelhos. Aorta com superfície irregular e formação de placas mineralizadas. 


\section{RESULTADOS Intoxicação iatrogênica Histórico e sinais clínicos}

Os coelhos receberam a administração do composto vitamínico (ADE) no dia 1.4.1998 e foram encaminhados ao Setor de Anatomia Patológica PSA Embrapa/UFRRJ no dia 22.4.1998, com histórico de emagrecimento progressivo. O Coelho 52 já chegou morto e o coelho 51, ainda vivo, apresentava diarréia, abdômen com acentuada distensão decorrente de ascite (Fig.1A) e dispnéia moderada; durante o acompanhamento clínico, até o dia seguinte, quando foi a óbito, foram observadas fezes com síbalas pequenas e hiporexia.

\section{Achados de necropsia}

Coelho 51. No coração havia leve hidropericárdio, marcada dilatação de câmaras, presença de placas esbranquiçadas (mineralização), na superfície do endocárdio do átrio esquerdo e nas valvas mitral (Fig.1B) e tricúspide. As artérias aorta, carótidas, femorais e renais estavam mais rígidas, com a superfície intimal irregular e formação de placas irregulares e esbranquiçadas, mais evidentes na aorta. Havia também acentuada ascite com flocos de fibrina, discreto edema em mesentério e moderado edema retroperitoneal. $\mathrm{O}$ fígado estava moderadamente aumentado de volume, com coloração vermelhoescura, com lobulação evidente e áreas com aspecto de noz-moscada, principalmente ao corte. Os rins mostravam-se pouco aumentados de volume e com superfície subcapsular discretamente irregular. Havia leve a moderada congestão esplênica.

Coelho 52. Leve edema subepicárdico e mineralização sob a forma de placas esbranquiçadas no endocárdio do coração esquerdo (átrio, cordas tendíneas e valva mitral) foram os principais achados. As artérias aorta (porções torácica e abdominal), carótidas, subclávias, femorais, renais e mesentéricas apresentavam intensa mineralização e rigidez. Observaram-se também moderado hidrotórax e edema subpleural, além de acentuada ascite com flocos de fibrina e edema subperitoneal. $\mathrm{O}$ fígado estava aumentado de volume, congesto, com aspecto de noz-moscada na superfície de corte. No estômago havia edema e hemorragia subserosos nas proximidades do cárdia; algumas áreas de hemorragia por diapedese foram observadas no intestino delgado. Nos rins observaram-se edema perirrenal, superfície finamente irregular, com pontilhado vermelho sob a cápsula e moderada congestão. O baço estava leve a moderadamente congesto.

\section{Achados clínicos (Exp.1)}

\section{Intoxicação experimental}

Os sintomas tiveram início entre $62 \mathrm{~h}$ a $127 \mathrm{~h}$ após a $1^{\mathrm{a}}$ aplicação de vitamina D3 e caracterizavam-se por hiporexia, emagrecimento, redução do volume fecal com síbalas de tamanho reduzido, enegrecidas e, por vezes, úmidas e amolecidas ou ressecadas; alguns coelhos apresentaram, eventualmente, diarréia mucosa. A evolução do quadro clí- nico oscilou de 49h e 30min (Coelho 6) a quase 22 dias (Coelho 7). Os sintomas evoluíram para anorexia e apatia/ depressão; alguns coelhos também apresentaram ranger de dentes, incoordenação, dificuldade respiratória (respiração profunda e lenta), exsudação nasal mucosa e parada respiratória. A redução de peso foi de 14 a $27 \%$. Oito dos nove coelhos tiveram morte espontânea, já o coelho 7 foi eutanasiado no 28을 dia de experimentação.

No Experimento 2, os animais não apresentaram sintomas.

\section{Achados de necropsia (Exp.1)}

No coração havia pontilhado esbranquiçado na base da mitral, com espessamento da mesma (Coelho 9) e no endocárdio do átrio esquerdo (Coelhos 7 e 9) sob forma de áreas difusamente esbranquiçadas. Discreta a moderada hipertrofia de ventrículo esquerdo e discreta a moderada dilatação de ventrículo direito também foram observadas, além de discreto derrame pericárdico (Coelho 5). A aorta exibia diversos graus de mineralização; externamente percebia-se, em alguns casos, aspecto mais rugoso e consistente; ao corte, a parede, muitas vezes, apresentava-se espessada e irregular, com superfície intimal rugosa e formação de placas branco-amareladas elevadas, de tamanhos variados, as quais se estendiam por toda a superfície ou ficavam intercaladas com áreas de superfície intimal macroscopicamente normais (Fig.1C). Tais alterações, em geral, eram mais pronunciadas na porção torácica. As artérias carótidas, renais e da parede do estômago também estavam mineralizadas em vários coelhos. Na porção inicial do tronco pulmonar foram observadas placas, semelhantes às encontradas na aorta, recobrindo a superfície interna. As veias cava, jugulares, renais e pulmonares estavam dilatadas. Áreas esbranquiçadas de mineralização na superfície peritoneal foram notadas nos Coelhos 5, 8 e 9.

A pleura parietal, na maioria dos coelhos, exibia áreas de mineralização, sob forma de estrias esbranquiçadas, por sobre a musculatura intercostal e costelas. Havia conteúdo espumoso de coloração rósea ou esbranquiçada, na traquéia e brônquios de quatro coelhos, bem como lobos pulmonares mais pesados, brilhantes e avermelhados em muitos casos; enfisema foi verificado em quatro coelhos; o coelho 5 apresentou superfície pulmonar discretamente áspera.

No estômago, geralmente, as paredes estavam espessadas em decorrência do evidente edema subseroso, muitas vezes, próximo à região do cárdia. Sob a serosa, foram evidenciadas áreas de mineralização (estrias ou pequenas placas esbranquiçadas, com extensão e localização variadas) em todos os coelhos. A mucosa gástrica geralmente apresentava áreas avermelhadas e elevadas. Havia, em geral, conteúdo líquido mucoso de coloração amarelo-esverdeada nas porções iniciais e conteúdo pastoso de coloração verde-escura nas porções finais do intestino delgado. Grande quantidade de conteúdo verdeescuro intenso no ceco, cólon com muco e reto com 
síbalas recobertas de muco eram achados comuns; no coelho 4 foram encontradas áreas avermelhadas (hemorragias) na serosa do ceco. O fígado apresentou lobulação um pouco mais evidente em muitos casos.

$\mathrm{O}$ achado mais comum no rim foi presença de discreta linha esbranquiçada na medula margeando a junção córtico-medular, além de congestão; o coelho 1 apresentou pontos esbranquiçados próximos à pelve e o Coelho 9 a junção córtico-medular mais esbranquiçada. Mosqueado marrom-claro foi visto externamente nos rins do Coelho 7.

Havia aumento da glândula tireóide, por vezes unilateral, em alguns coelhos.

\section{Achados de necropsia (Exp.2)}

Havia dilatação de ventrículo direito em dois coelhos (G2=C, G3=F), além de discreta irregularidade na íntima da aorta, no limite da visão a olho nu, em 3 coelhos ( $\mathrm{G} 1=\mathrm{A}$ e B, G2=C); nos coelhos do G3 (E e F) foram vistas discretas placas de mineralização, branco-amareladas e elevadas, na superfície intimal. A veia cava estava levemente dilatada no Coelho D (G2). Na pleura foram observadas estrias esbranquiçadas nos coelhos do G1 e G3 (A, $B, E, F)$, bem como na superfície peritoneal do Coelho $E$ (G3).

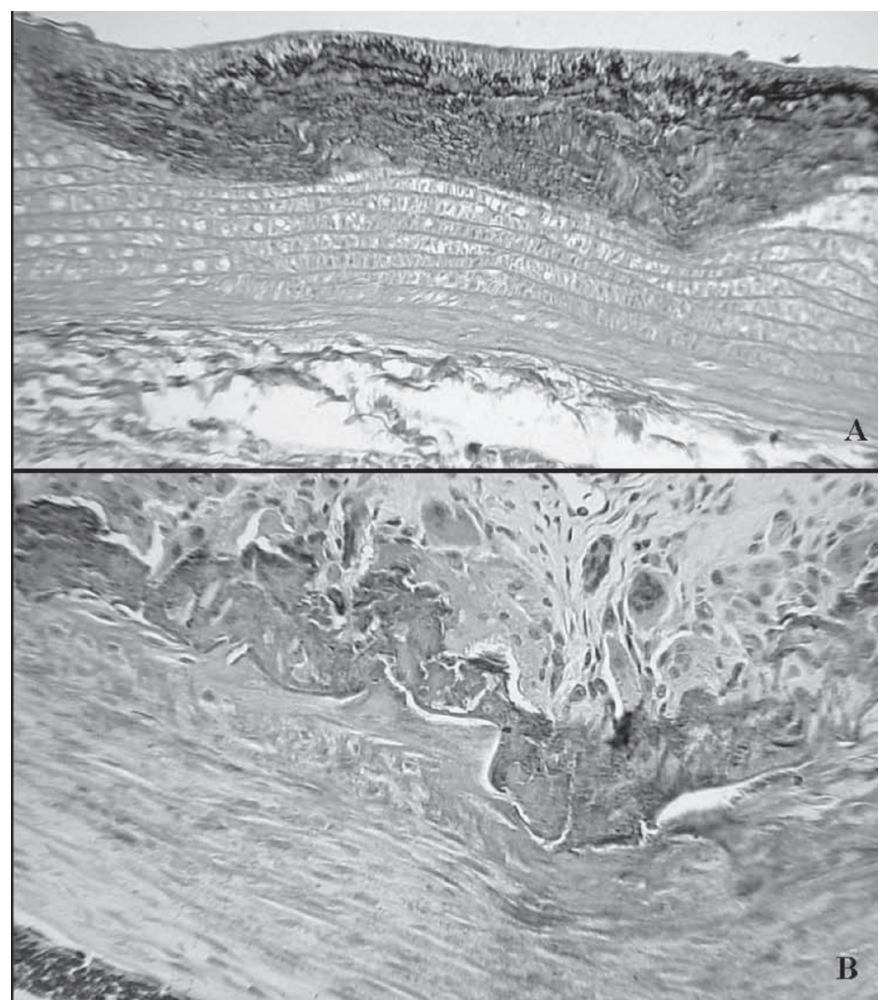

Fig.2. Intoxicação experimental por vitamina D em coelhos. (A) Aorta: áreas de mineralização da camada muscular e da parede da íntima; degeneração e metaplasia condróide incipiente da camada muscular (Coelho 1, SAP 29244). HE, obj.10x. (B) Aorta: mineralização e osseificação da camada média com presença de osteoclastos (Coelho 51, SAP 28508). HE, obj.10x.
Sob a serosa do estômago dos coelhos do G2 e G3 foram observados mineralização sob forma de estrias esbranquiçadas, edema (Coelhos $\mathrm{C}$ e $\mathrm{F}$ ) e mucosa com áreas avermelhadas (Coelhos $A, B, C, E, F)$. Os rins estavam úmidos ao corte ( $\mathrm{G} 1=\mathrm{A}, \mathrm{G} 2=\mathrm{C}, \mathrm{G} 3=\mathrm{F})$, mosqueados e com coloração pardo-amarelada (Coelho C e F), abrangendo do córtex até a junção córtico-medular. No Coelho C (G2) foram observados pontos brancos submiliares sob a cápsula e finas estrias brancas perpendiculares (paliçada) no córtex.

\section{Achados histopatológicos}

Os achados histopatológicos (Quadros 3 e 4) foram similares entre os coelhos das intoxicações iatrogênica e experimental, contudo eram mais marcados na intoxicação iatrogênica.

Aorta: a mineralização predominava na camada muscular e na íntima e, por vezes, era acompanhada por metaplasias óssea e condróide (Fig.2A,B). Um animal apresentou acentuada tumefação das fibras musculares. Coração: mineralização, caracterizada por depósitos gra-

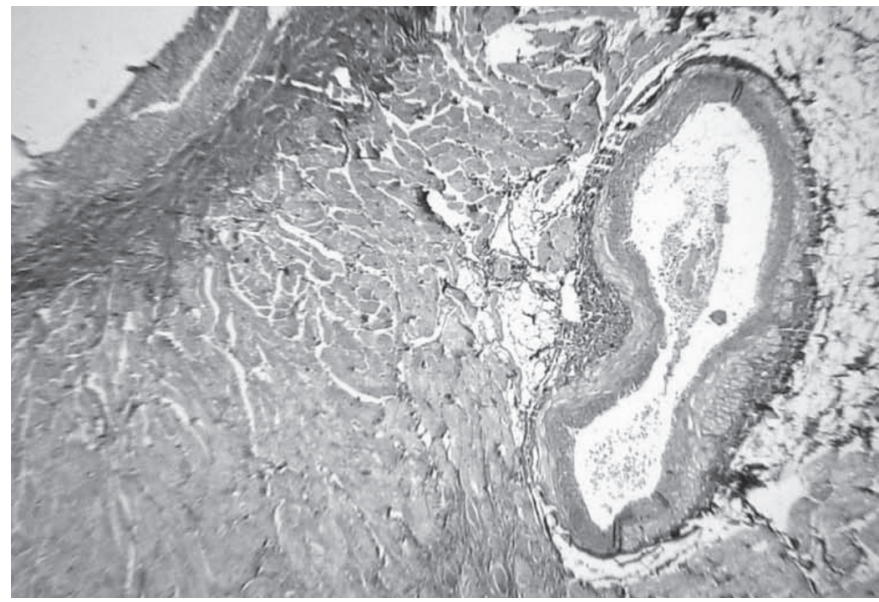

Fig.3. Intoxicação experimental por vitamina D em coelhos. Coração: mineralizações do endocárdio, miocárdio, artérias coronárias e colágeno do interstício pericoronariano (Coelho 7, SAP 29253). HE, obj.4x.

nulares ou pequenas placas basofílicas (Fig.3), foi verificada no endocárdio e nas artérias, por vezes acompanhada por metaplasia condróide e/ou óssea (Fig.4A,B) no miocárdio pericoronariano e também em artérias coronárias. Essa lesão, via de regra, intersticial, determinava atrofia e desaparecimento de fibras cardíacas. As valvas átrio-ventriculares encontravam-se espessadas por substância fundamental levemente basofílica, homogênea, associada, em apenas um caso, à mineralização. Proliferação de células mononucleares com aspecto de macrófagos foi observada com freqüência no interstício. Pulmão: variável grau de mineralização foi observado nas paredes alveolares e nas diversas camadas de brônquios e bronquíolos, inclusive epitélio. Havia, também, espessamento e mineralização de artérias e arteríolas, congestão e enfisema alveolar. No interstício foi verificada 


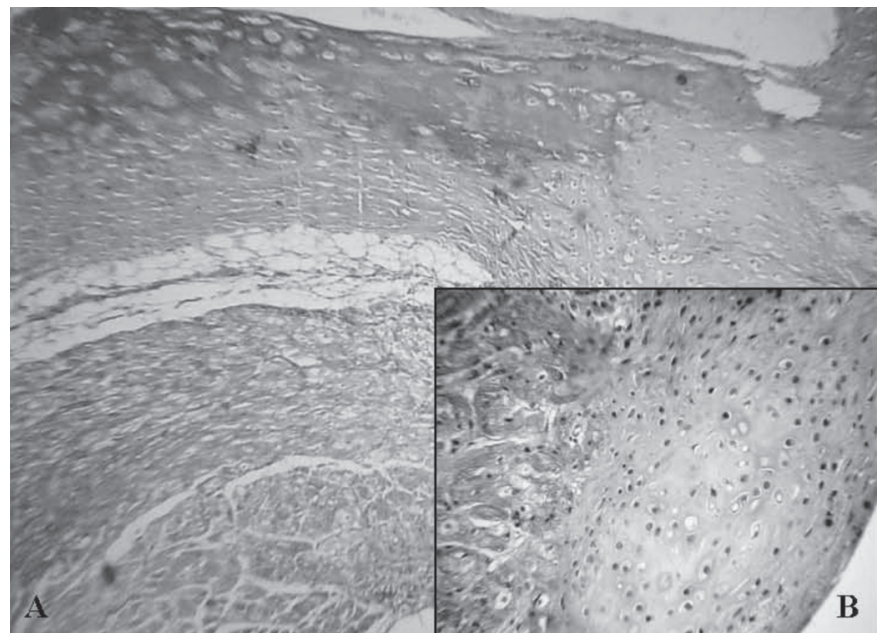

Fig.4. Intoxicação iatrogênica por vitamina D em coelhos. (A) Coração: metaplasia condróide e óssea do miocárdio na base da valva átrio-ventricular (Coelho 51, SAP 28508). HE, obj.4x. (B) Coração: metaplasia condróide na inserção da valva átrio-ventricular esquerda (Coelho 2, SAP 29117). HE, obj.25x.

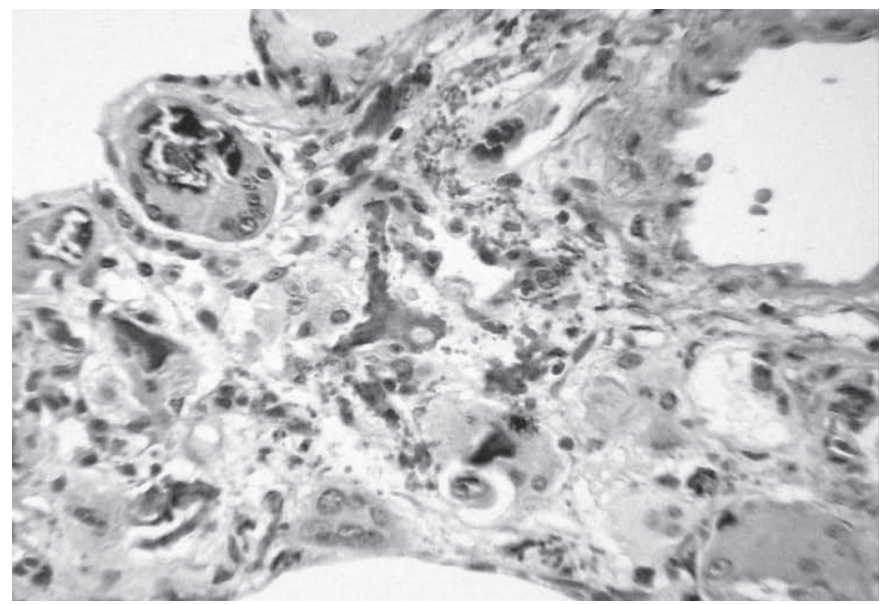

Fig.5. Intoxicação iatrogênica por vitamina D em coelhos. Pulmão: mineralização intersticial, proliferação de células mononucleares e metaplasia óssea incipiente com presença de osteoclastos (Coelho 51, SAP 28508). HE, obj.16x.

metaplasia osteo-condróide, com presença de osteoclastos (Fig.5) e proliferação de células mononucleares. Um animal, adicionalmente, apresentou peribronquiolite, trombose, leucocitoestase e pneumonia intersticial. Traquéia: mineralização e osseificação da cartilagem e de vasos da submucosa. Estômago: a mineralização era mais acentuada na camada muscular (Fig.6A), embora depósitos de mineral também estivessem presentes nas células epiteliais da mucosa e nas células parietais, e entre elas, no interstício da submucosa, na serosa e nos vasos das diversas camadas (Fig.6B). Adicionalmente foram observados congestão e edema da mucosa e da submucosa, assim como proliferação intersticial de células mononucleares semelhantes a macrófagos e atrofia das fibras da camada muscular adjacente às áreas mineralizadas. Rins: no córtex, evidente mineralização foi verificada nas cáp-

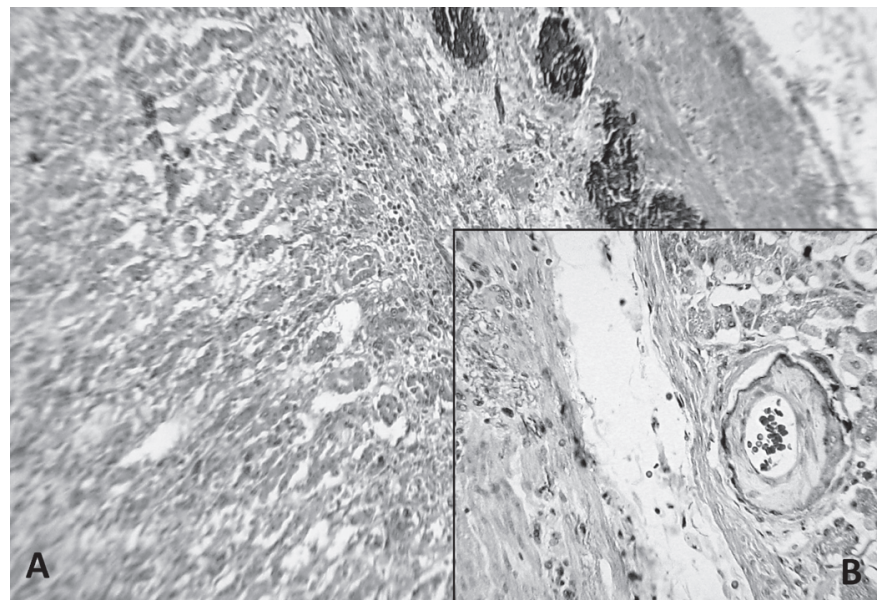

Fig.6. Intoxicação experimental por vitamina D em coelhos. (A) Estômago: áreas de mineralização da camada muscular (Coelho 1, SAP 29244). HE, obj.10x. (B) Estômago: mineralização de arteríola da mucosa e do interstício (Coelho 51, SAP 28508). HE, obj.25x.

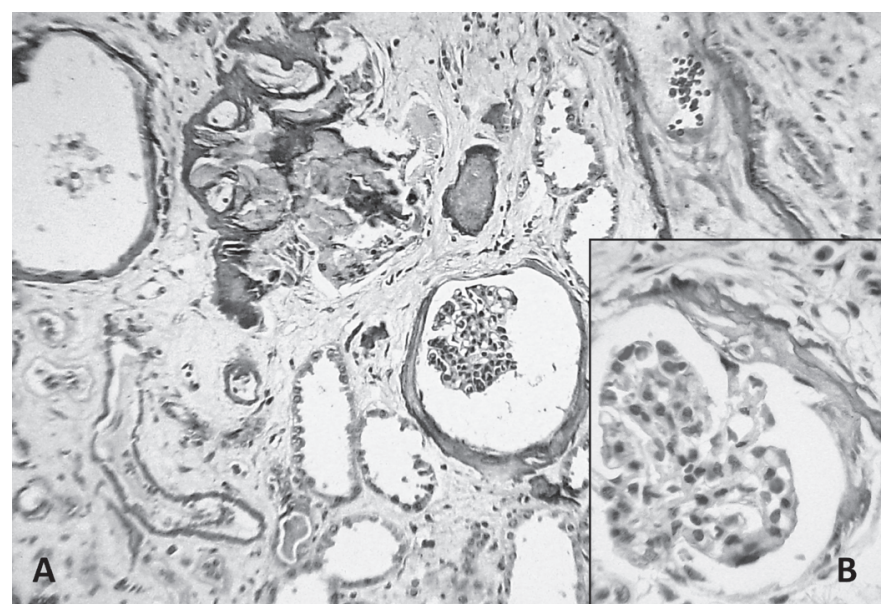

Fig.7. Intoxicação iatrogênica por vitamina $D$ em coelhos. (A) Rim: mineralização da cápsula de Bowmann, do interstício e dos túbulos uriníferos; edema e fibrose intersticial (CoeIho 51, SAP 28508). HE, obj.10x. (B) Mineralização e osseificação incipiente da cápsula de Bowmann (Coelho 51, SAP 28508). HE, obj.25x.

sulas de Bowmann, na membrana basal e no epitélio dos túbulos (Fig.7A,B); eventualmente, em artérias e no interstício, a mineralização ocorria associada a edema e a fibrose intersticial. Havia ainda congestão, dilatação dos espaços de Bowmann e de túbulos uriníferos com aumento do filtrado glomerular. Em um animal aparentemente havia osseificação incipiente da cápsula de Bowmann. Intestinos: foram observadas lesões similares às do estômago, porém bem menos marcadas. Fígado: grandes focos de vacuolização de hepatócitos e proliferação de células das vias biliares, congestão com degeneração hepatocelular secundária e evolução para lise. Observaram-se ainda edema, mineralização e osseificação das artérias da vesícula biliar; mineralização e osseificação vascular na língua; mineralização de vasos da glândula 


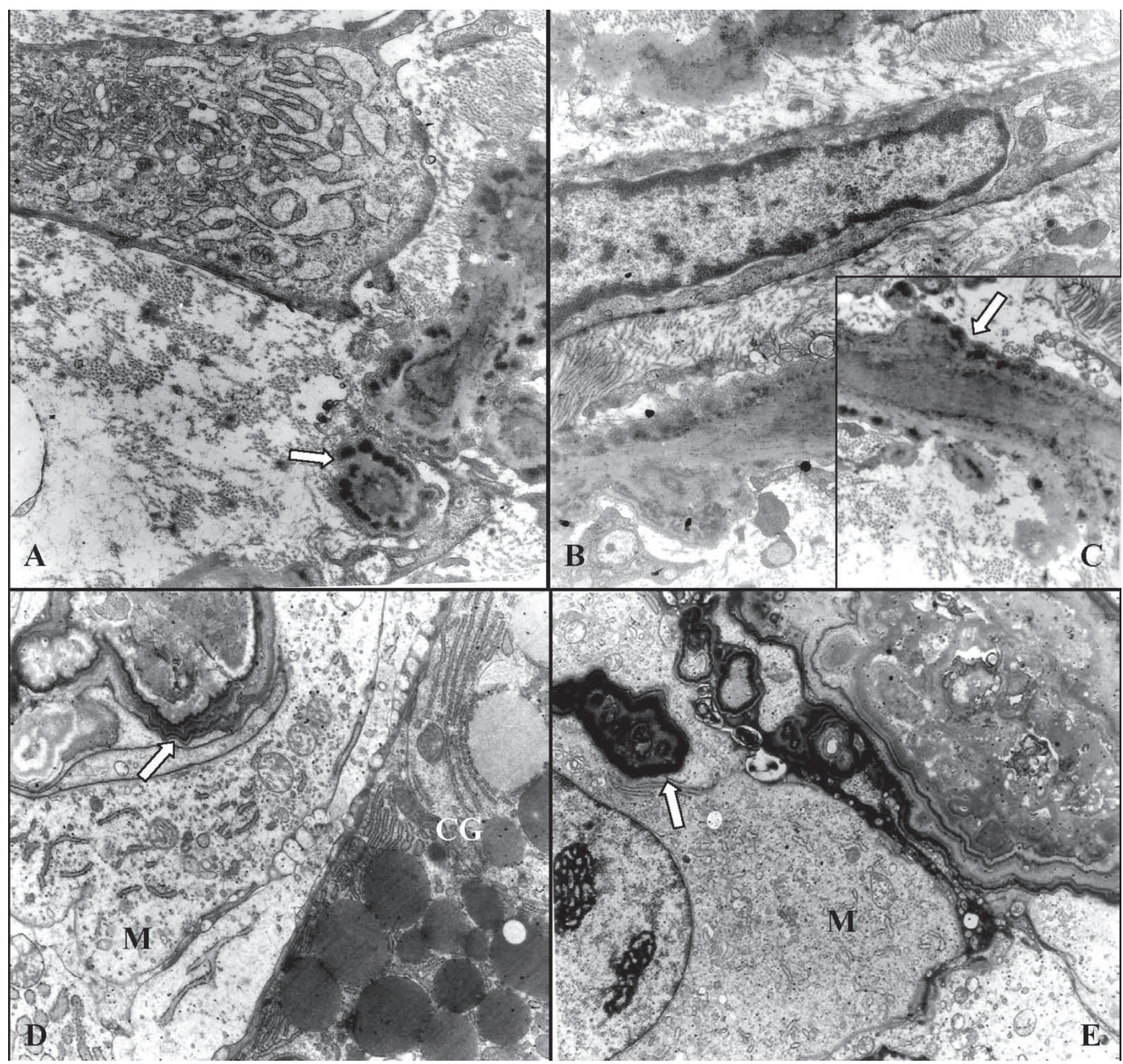

Fig.8. Intoxicação experimental por vitamina D em coelhos. (A) Aorta. Célula muscular lisa modificada com características de célula do tipo sintético, exibindo acentuada proliferação do aparelho de Golgi e do retículo endoplasmático rugoso. Algumas vesículas de pinocitose e elementos contráteis podem ser observados na periferia da célula. Lâminas elásticas parcialmente calcificadas podem ser vistas no canto inferior direito (seta). 12.600x (ME0703). (B) Aorta. Célula muscular lisa do tipo sintético junto a lâminas elásticas parcialmente calcificadas. 12.600x (ME0705). (C) Aorta. Lâmina elástica em maior aumento, evidenciando delicados cristais de cálcio na periferia (seta). 21.600x (ME0704). (D) Mucosa do estômago. Grande cristal de cálcio de aspecto laminar concêntrico (seta) junto a macrófago $(\mathrm{M})$ na lâmina própria. Célula glandular (CG) com grânulos de secreção vistos no canto inferior direito. 7.900x (ME0708). (E) Mucosa do estômago. Cristais de cálcio na lâmina própria exibindo formações de aspecto concêntrico (seta) junto a macrófagos (M). A seta mostra uma dessas formações aparentemente dentro do citoplasma, mas na verdade trata-se de incidência de corte. 7.900x (ME0686). (ME = número de registro da microscopia eletrônica)

salivar; artérias do útero com mineralização na muscular, edema na íntima e redução do lúmen, além de edema difuso na parede uterina; moderada quantidade de hemossiderina, mineralização de artéria centro-folicular e congestão do baço; em um caso, grande cisto na tireóide e, em um caso, foco de hiperplasia do córtex da adrenal.

\section{Achados ultraestruturais}

$\mathrm{Na}$ aorta e na parede do estômago, as alterações ultramicroscópicas caracterizaram-se pela transformação das células musculares lisas, do tipo contrátil, em células do tipo sintético, representada por incremento do retículo endoplasmático rugoso e do sistema de Golgi (Fig.8A), acentuada diminuição dos elementos contráteis, perda parcial ou total da membrana basal e presença de vesículas pinocíticas. As lâminas elásticas exibiam delicados cristais na periferia ou apresentavam-se parcialmente calcificadas (Fig.8B,C). Particularmente notável era o aparecimento de extensas áreas de mineralização intersticial, com formação de estruturas concêntricas (Fig.8D,E), tanto nas artérias como na muscular e mucosa do estômago. Macrófagos ativados foram freqüente- 


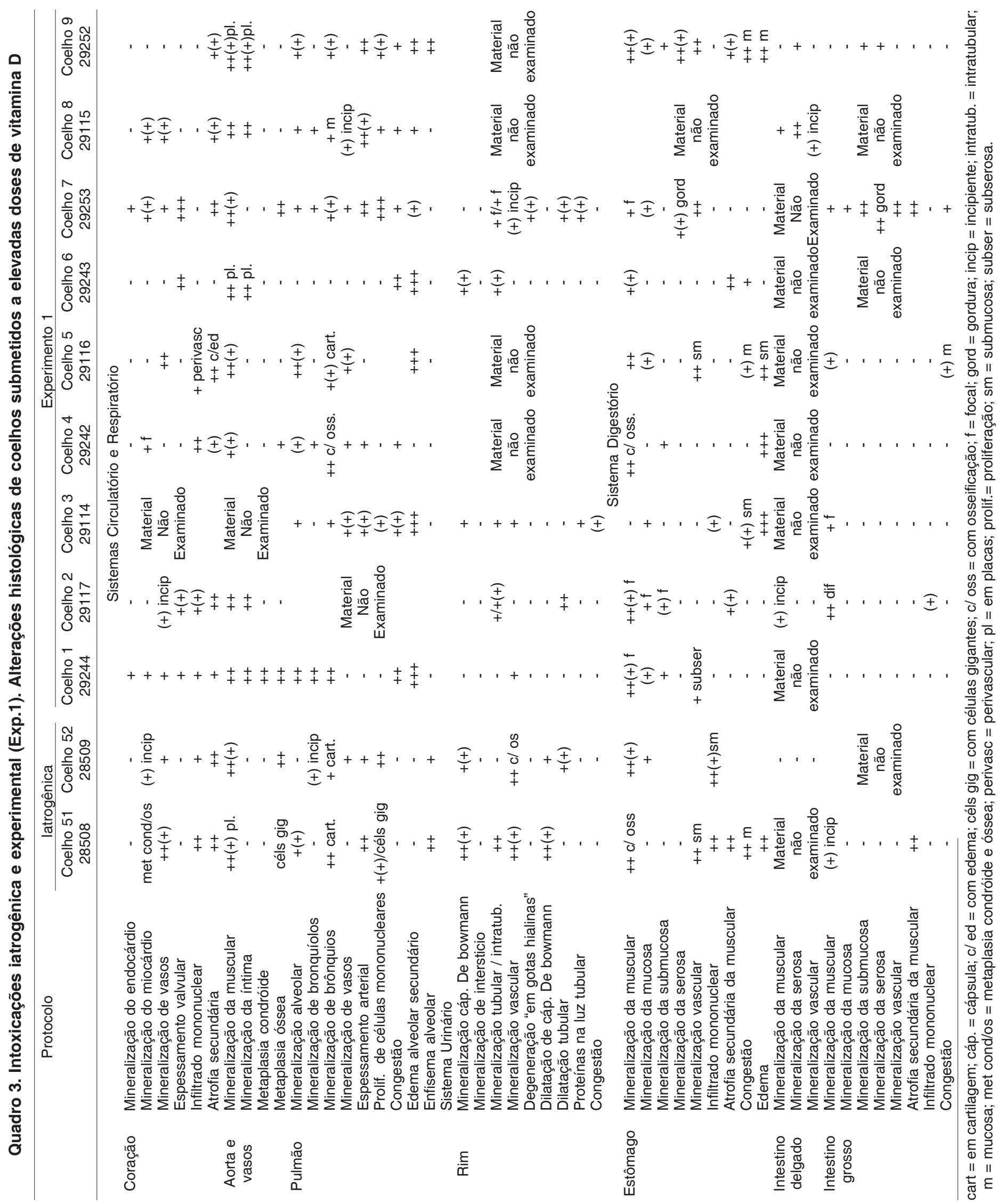


Quadro 4. Intoxicação experimental (Exp.2). Alterações histológicas de coelhos submetidos a elevadas doses de vitamina $D$

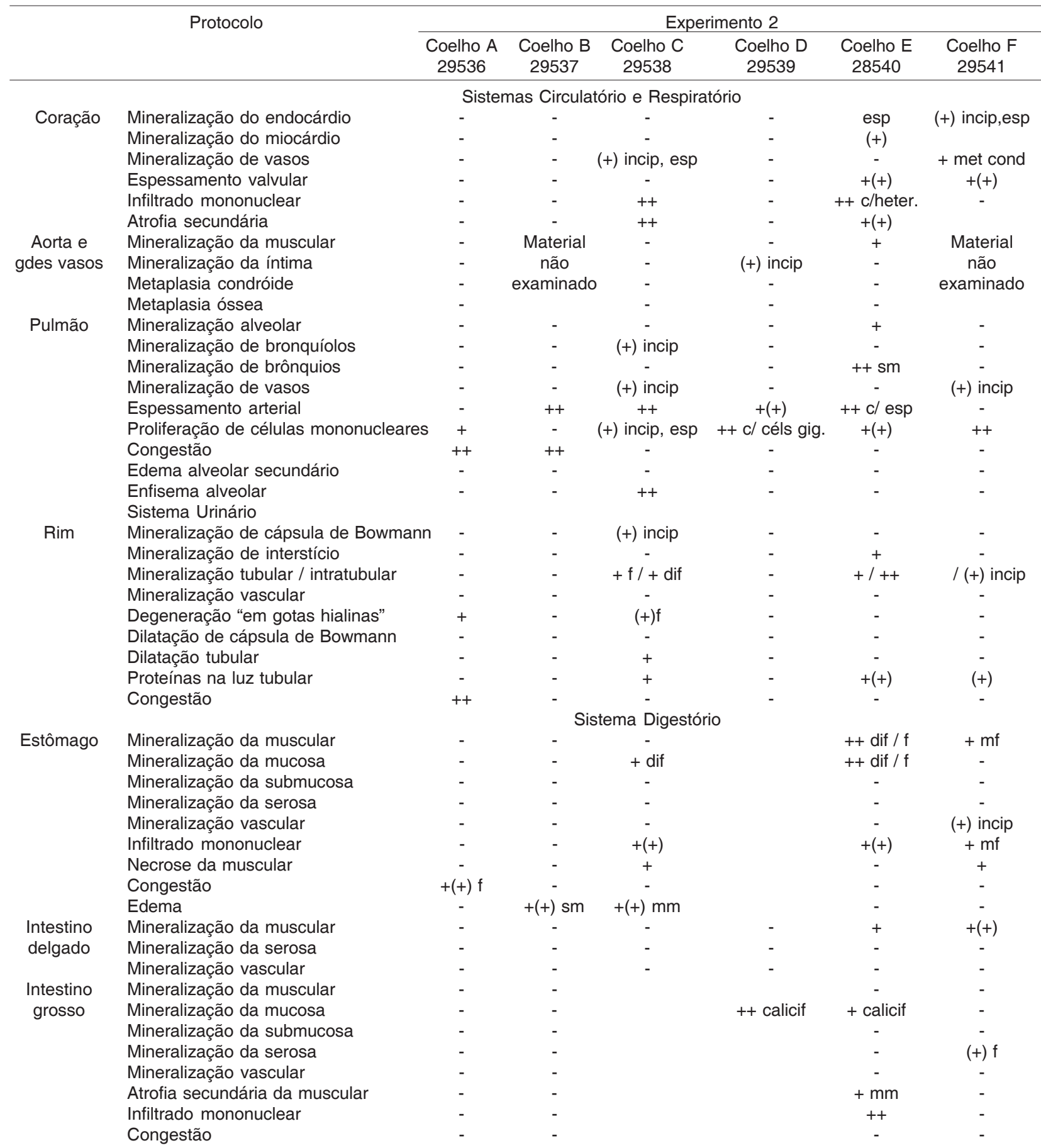

calicif = em células caliciformes; $\mathrm{c} /$ céls gig. = com células gigantes; c/heter = com heterófilos; dif = difusa; esp = espessamento; $\mathrm{f}=$ focal; incip = incipiente; $\mathrm{m}=$ mucosa; $\mathrm{mf}=$ multifocal; $\mathrm{mm}=$ camada muscular; met cond = metaplasia condróide; sm= submucosa.

mente vistos nas áreas próximas aos focos de mineralização (Fig.8D,E).

\section{DISCUSSÃO}

\section{Aspectos toxicológicos}

A ocorrência de intoxicação iatrogênica com vitamina D, por via subcutânea, até onde sabemos, não havia sido relatada em qualquer espécie; experimentalmente, porém, a via subcutânea já foi utilizada para se demonstrar o efeito teratogênico em coelhos do calcipotriol, um derivado da vitamina $\mathrm{D}$ utilizado no tratamento da psoríase (Uchiyama et al. 1996). Demonstra-se, desta forma, o potencial desta via de administração para intoxicar coelhos, visto que quadros clínico-patológicos semelhantes foram encontra- 
dos em coelhos intoxicados com vitamina $\mathrm{D}$, ou com plantas que a contenham, por via oral (Stevenson et al. 1976, Barros et al. 1981, 1996, Rambeck et al. 1981, Riet-Correa et al. 1981, Toda et al. 1983, Besch-Williford et al. 1985, Barros 1989, Zimmerman et al. 1990, Moraña et al. 1994, Barros \& Rosa 1999, Gomar et al. 2000, Matias et al. 2008), por via endovenosa (Moraña et al. 1994) e por via intramuscular (Hass et al. 1960, Friedman \& Roberts 1966, Stehbens 1988, Jiang et al. 1990, 1991).

Quanto à sensibilidade dos coelhos à intoxicação pela via subcutânea, uma análise comparativa com os outros relatos é difícil pelas diferenças nas doses e tempo de experimentação descritos e, principalmente, pelo fato de que diferentes compostos com atividade de vitamina $D$ (metabólitos ativados ou não-ativados e substâncias análogas) possuem graus variados de toxidez e muitos trabalhos não especificam a substância utilizada.

Uma vez que a hidroxilação do colecalciferol no fígado não é rigorosamente regulada (Dawson-Hughes 1997) e que também pode ocorrer em menor escala nos rins e intestinos (Granner 1998), o fato dos coelhos deste estudo terem sido intoxicados com colecalciferol (vitamina D3 não-ativada) possibilita sugerir-se que a regulação homeostática na ação da 1a-hidroxilase ( $2^{\mathrm{a}}$ hidroxilação) pode ser suprimida por níveis elevados de $25(\mathrm{OH})$ colecalciferol, conforme descreve Dawson-Hughes (1997), ou que o próprio $25(\mathrm{OH})$ colecalciferol poderia ser responsável pela intoxicação, assim como sugere Toda et al. (1983), ao observarem marcado aumento desse metabólito (30 vezes) no sangue de coelhos intoxicados com colecalciferol por via oral.

Este estudo e todos os demais relatos de intoxicação por vitamina $D$, em diversas espécies, demonstram a elevada toxidez desta vitamina independentemente da via de administração e o risco à saúde de seres humanos e animais que erros na sua suplementação representam.

\section{Aspectos clínicos}

Hiporexia e anorexia, emagrecimento, diarréia mucosa e presença de fezes com síbalas pequenas, enegrecidas e ressecadas foram as alterações mais freqüentes nos coeIhos deste estudo. Essas alterações também foram total ou parcialmente descritas em coelhos intoxicados com Solanum malacoxylon (Moraña et al. 1994), por Nierembergia veitchii (Riet-Correa et al. 1981) - importantes plantas calcinogênicas, por rações com níveis elevados de vitamina D (Stevenson et al. 1976, Rambeck et al. 1981, Besch-Williford et al. 1985, Zimmerman et al. 1990), em cães intoxicados com vitamina D2 (Spangler et al. 1979), em ratos intoxicados com vitamina D2 (Okawa et al. 1980) e vitamina D3 (Buffenstein et al. 1995), em cabras intoxicadas com colecalciferol (Singh \& Prasad 1989 e 1990), em ovinos intoxicados com Nierembergia veitchii (Barros et al. 1992) e em bovinos intoxicados com Solanum malacoxylon (Döbereiner et al. 1971, Tokarnia \& Döbereiner 1974).

Apatia também foi um sintoma bastante comum observado em coelhos do nosso estudo intoxicados iatrogênica e experimentalmente e talvez seja decorrente da insuficiência do coração. Este sintoma foi descrito em coelhos intoxicados com Solanum malacoxylon (Moraña et al. 1994), em caprinos intoxicados com colecalciferol por via intramuscular (Singh \& Prasad 1989 e 1990), em cães intoxicados com vitamina D2 (Spangler et al. 1979) e por vitamina $D$ em rodenticida (Cumming 1991), em um gato intoxicado por vitamina $\mathrm{D}$ em rodenticida (Peterson et al. 1991) e em ratos intoxicados com vitamina D3 (Buffenstein et al. 1995).

\section{Aspectos macroscópicos}

Os achados de necropsia encontrados neste estudo, correspondem, em sua maioria, aos encontrados em coelhos e em outras espécies intoxicadas por vitamina D. As placas de mineralização esbranquiçadas e de tamanhos variados no tronco das artérias pulmonares até cerca de $1,5 \mathrm{~cm}$ após a saída do ventrículo direito, foram observadas em alguns coelhos do experimento 01 desse estudo. Este achado é pouco comum e foi descrito em coelhos (Stehbens 1988) e em cães (Spangler et al. 1979). Mineralização de valvas cardíacas, encontrada em coeIhos desse estudo, também foi descrita em caprinos intoxicados com colecalciferol (Singh \& Prasad 1990), em bovinos intoxicados com Solanum malacoxylon (Döbereiner et al. 1971, Tokarnia \& Döbereiner 1974) e em ovinos intoxicados com Nierembergia veitchii (Riet-Correa et al. 1993).

As alterações encontradas no estômago foram, em sua maioria, idênticas às descritas por Moraña et al. (1994) em coelhos intoxicados experimentalmente com extrato de Solanum malacoxylon, entretanto, esse autor descreve edema entre a mucosa e as camadas musculares, enquanto que, em alguns coelhos dos experimentos $01 \mathrm{e}$ 02, o edema ocorreu tanto na submucosa quanto entre a serosa e a camada muscular. Moraña et al. (1994) sugere que o princípio tóxico da Solanum malacoxylon 1,25(OH)2colecalciferol - age diretamente afetando a permeabilidade vascular ou através da liberação de mediadores a partir das células lesadas.

Fígado cardíaco e a acentuada ascite encontrada no coelho 51, decorrente da insuficiência cardiovascular, até onde sabemos, não foi descrita em coelhos intoxicados por vitamina $D$, mas foi descrita em ovinos intoxicados com Nierembergia veitchii, os quais apresentaram, adicionalmente, hidrotórax e hidropericárdio (Barros et al. 1992).

\section{Aspectos histopatológicos}

Em nosso estudo, as alterações histológicas não diferem substancialmente do que vem sendo descrito nos casos de intoxicação por vitamina $D$ em coelhos ou de intoxicação por plantas que a contenham (Friedman \& Roberts 1966, Stevenson et al. 1976, Barros 1981, Riet-Correa et al. 1981, Rambeck et al. 1981, Toda et al. 1983, BeschWilliford et al. 1985, Zimmerman et al. 1990, Moraña et al. 1994, Barros \& Rosa 1999, Matias et al. 2008) e também 
correspondem, em grande medida, às observadas nas intoxicações por plantas calcinogênicas em ovinos (Barros et al. 1992, Riet-Correa et al. 1993) e em bovinos (Döbereiner et al. 1971, Tokarnia \& Döbereiner 1974).

As metaplasias óssea e condróide verificadas em artérias e na musculatura do estômago e do coração, a nosso ver, confirmam a teoria da ação da vitamina $\mathrm{D}$ em receptores nas células-alvo, a qual determina a síntese protéica ao nível celular por meio da ativação de sequências genéticas particulares e controla os processos metabólicos celulares e, em especial, a diferenciação celular como sustentam Barros (1989 e 1999), Moraña et al. (1994) e Barros \& Gimeno (2000). A mineralização da cápsula de Bowmann também foi descrita em caprinos intoxicados com colecalciferol (Singh \& Prasad 1990), em coelhos que recebiam ração rica em vitamina $D$ e cálcio (Matias et al. 2008) e em gatos intoxicados por vitamina $D$ em rodenticida (Peterson et al. 1991) e em ratos intoxicados com vitamina D2 (Okawa et al. 1980). É possível que eventualmente haja receptores para essa vitamina em células da cápsula de Bowmann, nas células parietais do estômago e nas células epiteliais de brônquios e bronquíolos já que se verificaram depósitos de mineral nessas estruturas.

É provável que a trombose pulmonar observada em um coelho esteja associada a lesões da íntima determinadas pela estase decorrente da insuficiência do coração; lesão direta pelo princípio ativo, porém, não pode ser descartada. Já a congestão hepática verificada em alguns animais está claramente associada à insuficiência cardiovascular.

\section{Aspectos ultraestruturais}

As alterações ultraestruturais são coincidentes com aquelas já descritas em outras oportunidades e confirmam verificações anteriores de que a vitamina $D$ tem ação direta sobre as células-alvo induzindo modificações morfológicas e funcionais que no caso das intoxicações, culminam com mineralizações ectópicas (Barros et al. 1981, Barros et al. 2000, Barros et al. 2006) particularmente das artérias, válvulas cardíacas, pulmões, alterações ósseas, distúrbios gastrintestinais e metabólicos.

A Figura 8C mostra uma típica célula muscular lisa modificada (diferenciada) junto a lâminas elásticas parcialmente calcificadas, que confirma que o princípio ativo deve provocar uma alteração celular local, antes da calcificação do tecido elástico (Barros et al. 1981).

Agradecimentos.- Ao Prof. Severo Sales de Barros, mestre a quem devemos significativa parte da nossa formação como patologista, pela realização, descrição e interpretação do estudo ultramicroscópico.

\section{REFERÊNCIAS}

Barros S.S. 1989. Aspectos ultraestruturais da calcinose experimental induzida por plantas. Saúde 15:241.

Barros S.S. \& Rosa F.G. 1999. Proliferação de macrófagos e células gigantes multinucleadas na mucosa bronquial e traqueal de coelhos experimentalmente intoxicados com S. glaucophyllum (Solanum malacoxylon). Anais 9 Enapave, Belo Horizonte, MG.

Barros S.S. \& Gimeno E.J. 2000. Cell differentiation and bone protein synthesis in lung of sheep with spontaneous calcinosis. J. Comp. Pathol. 123:270-277.

Barros S.S., Tabone E., Santos M., Andujar M. \& Grimaud J.A. 1981. Histopathological and ultrastructural alterations in the aorta in experimental Solanum malacoxylon poisoning. Virchows Arch. 35:169175

Barros S.S., Driemeier D., Santos M.N. \& Guerrero J.A.M. 1992. Evolução clínica e reversibilidade das lesões da calcinose enzoótica dos ovinos induzida por Nierembergia veitchii. Pesq. Vet. Bras., 12(1/2):510.

Barros S.S., Russowski D. \& Grando S.M. 1996. Ultra-estrutura das alterações ósseas na intoxicação experimental por Solanum malacoxylon em coelhos. Pesq. Vet. Bras.16(2/3):81-86.

Barros S.S., Soares M.P. \& Gimeno E.J. 2006. Macrophages and giant cell proliferation associated with bone protein synthesis and calcification in the trachea and bronchi of rabbits with Solanum glaucophyllum. Vet. Path. 43:494-499.

Besch-Williford C., Matherne C. \& Wagner J. 1985. Vitamin D toxicosis in commercially reared rabbits. Lab. Anim. Sci. 35(5):528.

Buffenstein R., Laundy M.T., Pitcher T. \& Pettifor J.M. 1995. Vitamin D3 intoxication in naked mole-rats (Heterocephalus glaber) leads to hypercalcaemia and increased calcium deposition in teeth with evidence of abnormal skin calcification. Gen. Comp. Endocrinol. 99:3540.

Cumming C. 1991. Suspected vitamin D rodenticide poisoning in a dog. Vet. Rec. 22:600.

Dawson-Hughes B. 1997. Vitamina D, p.1502-1503. In: Bennett J.C. \& Cecil P.F. (Eds), Tratado de Medicina Interna. Vol.2. $2^{\mathrm{a}}$ ed. Guanabara Koogan, Rio de Janeiro.

Döbereiner J., Tokarnia C.H., Costa J.B.D., Campos J.L.E. \& Dayrell M.S. 1971. "Espichamento", intoxicação de bovinos por Solanum malacoxylon no Pantanal de Mato Grosso. Pesq. Agropec. Bras. 6:91117

Friedman W.F. \& Roberts W.C. 1966. Vitamin D and supravalvular aortic stenosis syndrome: The transplacental effects of vitamin $D$ on the aorta of the rabbit. Am. Heart Assoc. Inc. Circulation 34:77-86.

Gomar M.S., Portiansky E.L., Dallorso M.E., Barros S.S., Costa E.F. \& Gimeno E.J. 2000. Diferenciacion celular y sintesis de proteinas oseas en aorta y pulmones inducidas por plantas calcinogenicas. Anais Taller Internacional de Toxicosis por Plantas em Animales y Humanos, La Habana, Cuba.

Granner D.K., Murray R.K., Mayes P.A. \& Rodwell V.W. 1998. Hormônios que regulam o metabolismo do cálcio, p.539-546. In: Murray R.K. Granner D.K., Mayes P.A. \& Rodwell V.W. (Eds), Harper: Bioquímica. Um Livro Médico Lange. $8^{\mathrm{a}} \mathrm{ed}$. Atheneu, São Paulo.

Hass G.M., Trueheart R.E. \& Hemmens A. 1960. Experimental arteriosclerosis due to hypervitaminosis D. Am. J. Pathol. 37(5):521549

Jiang Y., Wang Y., Zhao J., Marchal G., Wang Y., Shen Y., Xing S., Zhang X. \& Baert A.L. 1990. Metastatic calcification within bone. The main cause of osteosclerosis in hypervitaminosis D3: Radiologicpathologic correlation. Invest. Radiol. 25:1188-1196.

Jiang Y., Wang Y., Zhao J., Marchal G., Wang Y., Shen Y., Xing S., Li R. \& Baert A.L. 1991. Bone remodeling in hypervitaminosis D3: Radiology, microangiographic, pathologic correlations. Invest. Radiol. 26:213-219.

Marcus R. 1996. Fármacos que afetam a calcificação e a renovação do osso: cálcio, fosfato, paratormônio, vitamina D3, calcitonina e outros compostos, p.1126-1146. In: Hardman J.G. \& Limbird L.E. (Eds), Goodman e Gilman, As Bases Farmacológicas da Terapêutica. Interamericana Editores. 9ª ed. McGraw-Hill, Rio de Janeiro. 
Matias A.S.A., Bruno S.F., Menezes R.C., Matias C.A.R. \& Tortelly R. 2008. Prevalência e aspectos anatomopatológicos da mineralização metastática em coelhos provenientes de biotérios e criação comercial do Estado do Rio de Janeiro, Brasil. Ciência Rural 38(1):155-160.

Mello J.R.B. \& Habermehl G. 1995. Substâncias com atividade similar à vitamina D3 em quatro plantas calcinogênicas. Pesq. Vet. Bras.15(2/ 3):73-78.

Moraña J.A., Barros S.S., Driemeier D. \& Flôres Y.E. 1994. Gastropatia em coelhos experimentalmente induzida pela planta calcinogênica Solanum malacoxylon. Pesq. Vet. Bras. 14:35-42.

Okawa H., Doi K., Yasoshima A., Fujita T. \& Okaniwa A. 1980. Pathology of experimental atherosclerosis: Changes of acute phase in rats loaded with vitamin D2 and cholesterol. Jpn. J. Vet. Sci. 42:623-633.

Peterson E.N., Kirby R., Sommer M. \& Bovee K.C. 1991. Cholecalciferol rodenticide intoxication in a cat. J. Am. Vet. Med. Assoc. 199(7):904906.

Rambeck W.A., Strohle H.G., Wetzel A. \& Zucker H. 1981. Calcinogenic activity of vitamin D3 and vitamin D3 palmitate in rat and rabbit. Int. J. Nutr. Res. 51(4):359-364.

Riet-Correa F., Méndez M.D.C., Schild A.L., Santos E.C. \& Scarsi R.M. 1981. Experimentos em coelhos sugerem Nierembergia veitchii como causa de calcinose enzoótica em ovinos do Rio Grande do Sul. Pesq. Agropec. Bras. 16(5):727-732.

Riet-Correa F., Méndez M.D.C., Schild A.L. \& Petiz C.A. 1993. Enzootic calcinosis in sheep: Experimental reproduction with Nierembergia veitchii (Solanaceae). Pesq. Vet. Bras.13(1/2):21-24.
Singh S.K. \& Prasad M.C. 1989. Vitamin D induced arteriosclerosis in goats. Indian J. Anim. Sci. 59(9):1114-1117.

Singh S.K. \& Prasad M.C. 1990. Pathology of hypervitaminosis D in goats: An experimental study. Indian J. Anim. Sci. 60(3):295-301.

Spangler W.L., Gribble D.H. \& Lee T.C. 1979. Vitamin D intoxication and the pathogenesis of vitamin $\mathrm{D}$ nephropathy in the dog. Am. J. Vet. Res. 40(1):73-83.

Stehbens W.E. 1988. Localization of experimental calcification in rabbit blood vessels with particular reference to hemodynamics. Angiology 39(7):597-608.

Stevenson R.G., Palmer N.C. \& Finley G.G. 1976. Hipervitaminosis D in rabbits. Canine Vet. J. 17:54-57.

Toda T., Leszczynski D.E. \& Kummerow F.A. 1983. The role of 25hydroxy-vitamin D3 in the induction of atherosclerosis in swine and rabbit by hypervitaminosis D. Acta Pathol. Jpn. 33(1):37-44.

Tokarnia C.H. \& Döbereiner J. 1974. "Espichamento", intoxicação de bovinos por Solanum malacoxylon, no Pantanal de Mato Grosso. II. Estudos complementares. Pesq. Agropec. Bras. 9:53-62.

Uchiyama H., Suzuki T., Koike Y., Ono M., Shirakawa K., Nagata M. \& Konishi R. 1996. Reproductive and developmental toxicity studies of calcipotriol (MC903).3. A teratogenicity study in rabbits by subcutaneous administration. J. Toxicol. Sci. 21(suppl. 2):425-438.

Zimmerman T.E., Giddens W.E. Jr, DiGiacomo R.F. \& Ladiges W.C. 1990. Soft tissue mineralization in rabbits fed a diet containing excess vitamin D. Lab. Anim. Sci. 40(2):212-215. 